\title{
COMPARATIVE STUDY OF PULMONARY FUNCTION IN DIFFERENT TYPES OF SMOKERS
}

\author{
Abdul Majeed Arshad ${ }^{1}$, T. Dhanasekar ${ }^{2}$, Athira Joseph ${ }^{3}$, Hemanth. L', Sindhura Koganti ${ }^{5}$, B. Rajagopalan 6 \\ ${ }^{1}$ Assistant Professor, Department of Pulmonary Medicine, Sri Ramachandra Medical College and Hospital, Chennai. \\ ${ }^{2}$ Associate Professor, Department of Pulmonary Medicine, Sri Ramachandra Medical College and Hospital, Chennai. \\ ${ }^{3}$ Respiratory Therapist, Department of Pulmonary Medicine, Sri Ramachandra Medical College and Hospital, Chennai. \\ ${ }^{4}$ Senior Resident, Department of Pulmonary Medicine, Sri Ramachandra Medical College and Hospital, Chennai. \\ ${ }^{5}$ Assistant Professor, Department of Pulmonary Medicine, Sri Ramachandra Medical College and Hospital, Chennai. \\ ${ }^{6}$ Professor and HOD, Department of Pulmonary Medicine, Sri Ramachandra Medical College and Hospital, Chennai.
}

\section{ABSTRACT}

\section{OBJECTIVES}

The aim and objective of this study is to compare the pulmonary function variables with the help of spirometer among beedi smokers, cigarette smokers and subjects who smoked both beedi and cigarette.

\section{BACKGROUND}

Smoking is a major public health problem and a major cause of many preventable diseases and premature deaths all over the world. Pulmonary function variables will differ based on the type of smoking i.e. Beedi smokers, cigarette smokers, subjects who smoked both beedi and cigarette.

\section{METHODS}

Cross sectional study done on 90 male smokers attending the Pulmonary Outpatient Department of Sri Ramachandra Medical College and Hospital. Spirometry was done to assess the pulmonary function.

\section{CONCLUSION}

Pulmonary function values showed significant reduction in beedi smokers than people who smoke both beedi and cigarette, followed by subjects who smoked cigarette alone.

\section{KEYWORDS}

Spirometry, Pulmonary Function, Different Types of Smokers, COPD.

HOW TO CITE THIS ARTICLE: Abdul Majeed Arshad, T. Dhanasekar, Athira Joseph, Hemanth L, Sindhura Koganti, B. Rajagopalan. "Comparative Study of Pulmonary Function in Different Types of Smokers." Journal of Evolution of Medical and Dental Sciences 2015; Vol. 4, Issue 97, December 03; Page: 16205-16209, D0I: 10.14260/jemds/2015/2383

\section{INTRODUCTION}

Tobacco smoking is widely prevalent all over the world and it continues to rise in Developing countries, by 2030 the developing world is expected to have 7 million deaths annually from tobacco use.(1) Various forms of tobacco smoking are prevalent in India including smoking of beedies, cigarettes, cigars like cheroots, cigarillos and 'Hukka'.

Beedies are made from suncured tobacco rolled in tendu leaf wrapper about $6 \mathrm{~cm}$ long and do not have filters .Beedies produce 3 times more carbon monoxide and nicotine and 5 times more tar than normal cigarettes.(2) The absence of a filter and the poor porosity of the leaf used to wrap the tobacco causes the smoker to inhale more frequently and more deeply if the beedis is to remain alight. The net weight of tobacco per beedi averages from 150-240 mg.(3)

Bhinde studied the chemical analysis of smoke of Indian cigarettes, beedis and other ingenious forms of smoking levels of steam volatile phenol, hydrogen cyanide and benzopyrene. ${ }^{(4)}$ It has been well established that smoking is a major risk factor for lung cancer, coronary heart disease and chronic obstructive pulmonary disease (COPD).

Financial or Other, Competing Interest: None.

Submission 15-11-2015, Peer Review 16-11-2015,

Acceptance 24-11-2015, Published 01-12-2015.

Corresponding Author:

Dr. Abdul Majeed Arshad,

Old No. 24, New No. 4, 12 th Cross Street,

Shastri Nagar, Adyar

Chennai - 600020, Tamilnadu, India.

E-mail: dr.arshad.majeed@gmail.com

DOI:10.14260/jemds/2015/2383
Cigarette smoking for only a few years causes early changes in the peripheral airways of the lung.(5) The present study has been undertaken to compare the pulmonary function variables in these subjects. The spirometer is an effective and easy method for detection of COPD and thus promote smoking cessation efforts to reduce the burden of COPD and lung cancers in the community.

\section{MATERIALS AND METHODS}

\section{METHODOLOGY}

- Study Units: 90 male smokers from the Outpatient Department of Sri Ramachandra Medical College and Hospital.

- Study Design: Cross sectional study.

- Study Tools and Methods: Spirometer to assess pulmonary function.

Modified kuppuswamy scale to assess the socioeconomic status.

- Reference Period: June 01, 2015-Jan 30, 2015

- Inclusion Criteria: Male smokers in age group between 30-75.

- Exclusion Criteria: Non smokers, Sick patients.

Main Survey

- The subjects included in this study were 30 beedi smokers (Group1), 30 cigarette smokers (Group 2), 30 Smokers who smoked both beedi as well as cigarette (Group 3).

- Smoking history was noted and smoking index were calculated for all the subjects. 
- Socioeconomic status was assessed as per modified kuppuswamy scale.

- Pulmonary function of the subjects enrolled in our study was assessed with the help of a spirometer.

\section{SPIROMETRY}

Spirometry is the most frequently used measure of lung function and is a measure of volume against time.

Measurements that are made include.

- Forced expiratory volume in one second (FEV1).

- Forced vital capacity (FVC).

- The ratio of the two volumes (FEV1/FVC).

- Forced Expiratory Flow Rate.

\begin{tabular}{|l|}
\hline \multicolumn{2}{|c|}{$\begin{array}{l}\text { Severity of airflow obstruction based on percentage (\%) } \\
\text { predicted forced expiratory volume in I second (FEVI). }\end{array}$} \\
\begin{tabular}{|l|l|}
\hline FEV1 \% predicted & Stage \\
\hline$>80 \%$ & Mild \\
\hline $50-79 \%$ & Moderate \\
\hline $30-49 \%$ & Severe \\
\hline$<30 \%$ & Very severe \\
\hline
\end{tabular}
\end{tabular}

\section{KUPPUSWAMY'S SOCIO-ECONOMIC STATUS SCALE}

Socioeconomic status (SES) refers to an individual's position within a hierarchical social structure, which is one of the important determinants of health status. The Kuppuswamy scale measures the SES of an individual based on three variables namely, education and occupation of the head of the household and income of the family.

\section{RESULTS AND OBSERVATIONS}

PFT carried out among 90 subjects (Male) to compare pulmonary function variables in type of smoking. The number of years of smoking and number of cigarettes/beedi smoked/ day had great impact on the PFT values. The PFT values were drastically decreased among these categories.

\section{Table 1}

\begin{tabular}{|c|c|c|c|c|c|c|c|c|}
\hline \multicolumn{9}{|c|}{ Descriptives } \\
\hline \multicolumn{9}{|c|}{ SMOKING INDEX } \\
\hline & \multirow[b]{2}{*}{$\mathrm{N}$} & \multirow[b]{2}{*}{ Mean } & \multirow[b]{2}{*}{ Std. Deviation } & \multirow[b]{2}{*}{ Std. Error } & \multicolumn{2}{|c|}{$\begin{array}{l}\text { 95\% Confidence Interval for } \\
\text { Mean }\end{array}$} & \multirow[b]{2}{*}{ Minimum } & \multirow[b]{2}{*}{ Maximum } \\
\hline & & & & & Lower Bound & Upper Bound & & \\
\hline GROUP 1 & 30 & 399.67 & 229.771 & 41.950 & 313.87 & 485.46 & 70 & 900 \\
\hline GROUP 2 & 30 & 124.27 & 138.267 & 25.244 & 72.64 & 175.90 & 8 & 450 \\
\hline GROUP 3 & 30 & 274.00 & 131.886 & 24.079 & 224.75 & 323.25 & 40 & 500 \\
\hline Total & 90 & 265.98 & 204.732 & 21.581 & 223.10 & 308.86 & 8 & 900 \\
\hline
\end{tabular}

Table 2

\begin{tabular}{|c|c|c|c|c|c|}
\hline \multicolumn{6}{|c|}{ ANOVA } \\
\hline & $\begin{array}{l}\text { Sum of } \\
\text { Squares }\end{array}$ & df & Mean Square & $\mathrm{F}$ & Sig. \\
\hline Between Groups & 1140573 & 2 & 570286.711 & 19.157 & .000 \\
\hline Within Groups & 2589883 & 87 & 29768.765 & & \\
\hline Total & 3730456 & 89 & & & \\
\hline
\end{tabular}

Table 3

\begin{tabular}{|c|c|c|c|c|c|c|}
\hline \multicolumn{7}{|c|}{ Multiple Comparisons } \\
\hline \multicolumn{7}{|c|}{$\begin{array}{l}\text { Dependent Variable: SMOKING INDEX } \\
\text { Tukey HSD }\end{array}$} \\
\hline \multirow[b]{2}{*}{ (l) GROUP } & \multirow[b]{2}{*}{ (J) GROUP } & \multirow{2}{*}{$\begin{array}{l}\text { Mean } \\
\text { Difference } \\
(1-J)\end{array}$} & \multirow[b]{2}{*}{ Std. Error } & \multirow[b]{2}{*}{ Sig. } & \multicolumn{2}{|c|}{$95 \%$ Confidence Interval } \\
\hline & & & & & Lower Bound & Upper Bound \\
\hline \multirow[t]{2}{*}{ GROUP 1} & GROUP 2 & $275.400^{*}$ & 44.549 & .000 & 169.17 & 381.63 \\
\hline & GROUP 3 & $125.667^{*}$ & 44.549 & .016 & 19.44 & 231.89 \\
\hline \multirow[t]{2}{*}{ GROUP 2} & GROUP 1 & $-275.400^{*}$ & 44.549 & .000 & -381.63 & -169.17 \\
\hline & GROUP 3 & $-149.733^{*}$ & 44.549 & .003 & -255.96 & -43.51 \\
\hline \multirow[t]{2}{*}{ GROUP 3} & GROUP 1 & $-125.667^{*}$ & 44.549 & .016 & -231.89 & -19.44 \\
\hline & GROUP 2 & $149.733^{*}$ & 44.549 & .003 & 43.51 & 255.96 \\
\hline
\end{tabular}


Table 4: Post Hoc Tests

Using Anova test there is significant difference among the Three Groups at ( $\mathrm{p}=0.001)$. Group 1 mean value is 399.67 and Group 2 mean value is 124.27 and Group 3 mean value is 274.00

Using Post Hoc Tests multiple comparisons taking HSD method. We found statistical significance between Group 1 and Group 2/Group 2 and Group 3/Group 1 and Group 3. All are statistically significant.



Fig.1: Group 1 patients had the highest smoking index, followed by Group 3 and Group 2 had the lowest smoking index

Table 5

\begin{tabular}{|c|c|c|c|c|c|c|c|c|}
\hline \multicolumn{9}{|c|}{ Descriptives } \\
\hline & \multirow[b]{3}{*}{$\mathrm{N}$} & \multirow[b]{3}{*}{ Mean } & \multirow[b]{3}{*}{ Std. Deviation } & \multirow[b]{3}{*}{ Std. Error } & \multirow{2}{*}{\multicolumn{2}{|c|}{$\begin{array}{l}\text { 95\% Confidence Interval for } \\
\text { Mean }\end{array}$}} & \multirow[b]{3}{*}{ Minimum } & \multirow[b]{3}{*}{ Maximum } \\
\hline & & & & & & & & \\
\hline & & & & & Lower Bound & Upper Bound & & \\
\hline GROUP 1 & 30 & 33.70 & 14.408 & 2.631 & 28.32 & 39.08 & 10 & 64 \\
\hline GROUP 2 & 30 & 65.77 & 16.796 & 3.067 & 59.49 & 72.04 & 32 & 95 \\
\hline GROUP 3 & 30 & 47.03 & 10.217 & 1.865 & 43.22 & 50.85 & 28 & 69 \\
\hline Total & 90 & 48.83 & 19.197 & 2.024 & 44.81 & 52.85 & 10 & 95 \\
\hline
\end{tabular}

Table 6

\begin{tabular}{|c|c|c|c|c|c|}
\hline \multicolumn{6}{|c|}{ ANOVA } \\
\hline \multicolumn{6}{|l|}{ FEV1 } \\
\hline & $\begin{array}{l}\text { Sum of } \\
\text { Squares }\end{array}$ & df & Mean Square & $\mathrm{F}$ & Sig. \\
\hline \begin{tabular}{|l|} 
Between Groups \\
\end{tabular} & 15569.867 & 2 & 7784.933 & 39.312 & .000 \\
\hline Within Groups & 17228.633 & 87 & 198.030 & & \\
\hline Total & 32798.500 & 89 & & & \\
\hline
\end{tabular}

Table 7: Post Hoc Tests

\begin{tabular}{|c|c|c|c|c|c|c|}
\hline \multicolumn{7}{|c|}{ Multiple Comparisons } \\
\hline \multicolumn{7}{|c|}{$\begin{array}{l}\text { Dependent Variable: FEV1 } \\
\text { Tukey HSD }\end{array}$} \\
\hline \multirow[b]{2}{*}{ (I) GROUP } & \multirow[b]{2}{*}{ (J) GROUP } & \multirow{2}{*}{$\begin{array}{c}\text { Mean } \\
\text { Difference } \\
(1-J)\end{array}$} & \multirow[b]{2}{*}{ Std. Error } & \multirow[b]{2}{*}{ Sig. } & \multicolumn{2}{|c|}{$95 \%$ Confidence Interval } \\
\hline & & & & & Lower Bound & Upper Bound \\
\hline \multirow[t]{2}{*}{ GROUP 1} & GROUP 2 & $-32.067^{*}$ & 3.633 & .000 & -40.73 & -23.40 \\
\hline & GROUP 3 & $-13.333^{\star}$ & 3.633 & .001 & -22.00 & -4.67 \\
\hline \multirow[t]{2}{*}{ GROUP 2} & GROUP 1 & $32.067^{\star}$ & 3.633 & .000 & 23.40 & 40.73 \\
\hline & GROUP 3 & $18.733^{*}$ & 3.633 & .000 & 10.07 & 27.40 \\
\hline \multirow[t]{2}{*}{ GROUP 3} & GROUP 1 & $13.333^{*}$ & 3.633 & .001 & 4.67 & 22.00 \\
\hline & GROUP 2 & $-18.733^{\star}$ & 3.633 & .000 & -27.40 & -10.07 \\
\hline
\end{tabular}


Using Anova test there is significant difference among the Three Groups at ( $\mathrm{p}=0.001)$. Group 1 mean value is 33.70 and Group 2 mean value is 65.7 and Group 3 mean value is 47.03.

Using Post Hoc Tests multiple comparisons taking HSD method. We found statistical significance between Group 1 and Group 2/Group 2 and Group 3/Group 1 and Group 3. All are statistically significant.

\begin{tabular}{|c|c|}
\hline \multicolumn{2}{|c|}{ FEV 1 } \\
\hline GROUP 1 & 33.7 \\
\hline GROUP 2 & 65.7 \\
\hline GROUP 3 & 47.03 \\
\hline
\end{tabular}

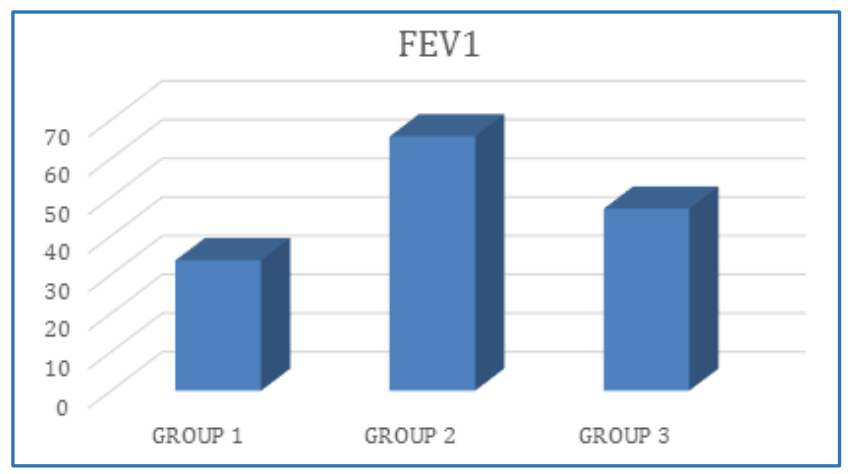

Fig. 2: The Group 1 subjects had lowest FEV1 followed by GROUP 3 and GROUP 1

\begin{tabular}{|l|c|c|c|c|c|}
\hline & UPPER & $\begin{array}{c}\text { UPPER } \\
\text { MIDDLE }\end{array}$ & $\begin{array}{c}\text { LOWER } \\
\text { MIDDLE }\end{array}$ & $\begin{array}{c}\text { UPPER } \\
\text { LOWER }\end{array}$ & LOWER \\
\hline GROUP 1 & 0 & 0 & 0 & 6 & 24 \\
\hline GROUP 2 & 6 & 10 & 11 & 3 & 0 \\
\hline GROUP 3 & 0 & 1 & 12 & 11 & 6 \\
\hline \multicolumn{7}{|c|}{ Table 8: Kuppuswamy's Socio Economic } \\
Status Scale among the Groups \\
\hline
\end{tabular}

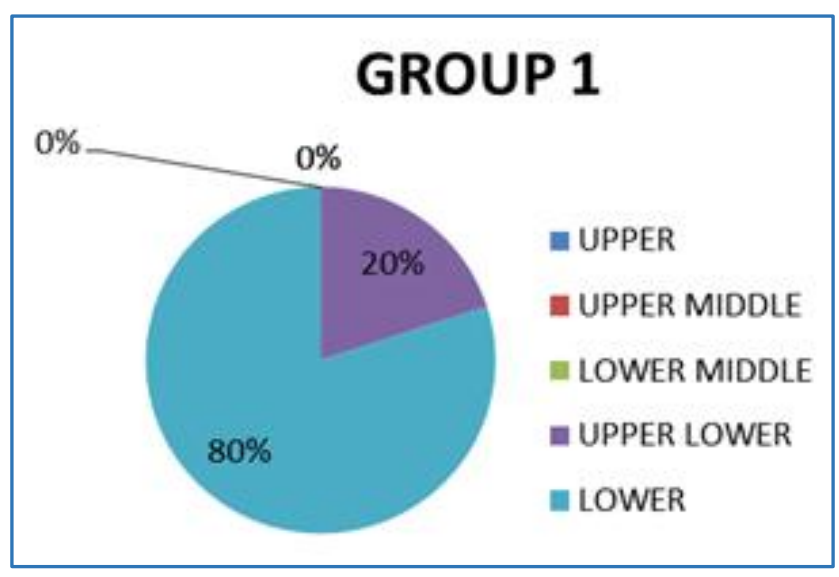

Fig. 3: Group 1 patients were mostly under LOWER and UPPER LOWER Socio-Economic Status Scale.

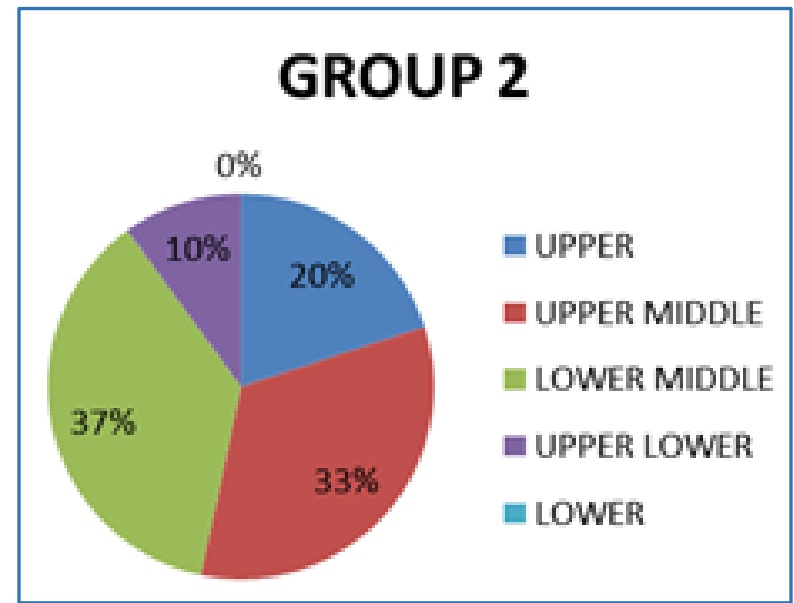

Fig.4: Group 2 patients were mostly distributed in UPPER MIDDLE and LOWER MIDDLE Socio-Economic Status Scale

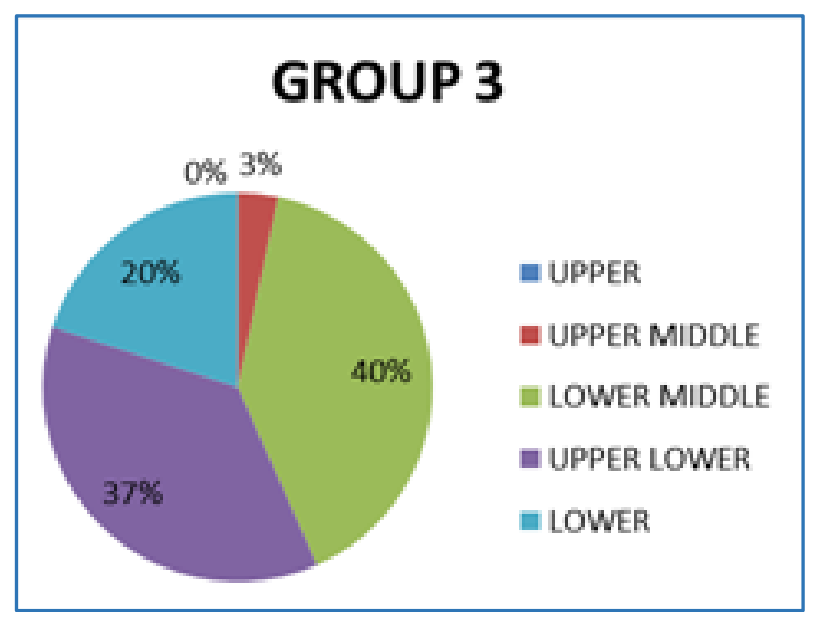

Fig.5: Group 3 patients predominantly were in LOWER MIDDLE and UPPER LOWER Socio-Economic Status Scale.

It concluded that cigarette smoking predominates in higher income group whereas beedi smoking is the commonest type of smoking in the lower income group.

\section{DISCUSSION}

It was initially thought that beedi smoking is less harmful than cigarette smoking although the studies carried out in India show it otherwise since the risk of cancer at oral cavity, pharynx, lung and oesophagus is more in beedi smokers than in cigarette smokers. $(6-9,10,11)$

A study done by K.M. Padmavathi et al concluded that pulmonary functions were poor in beedi smokers than in cigarette smokers. ${ }^{(8)}$

In our study, the values of FEV1 show significant reduction $(\mathrm{P}<0.001)$ in beedi smokers than cigarette smokers and subjects who smoked both beedi and cigarette. This can be accounted on the basis of excess of carbon monoxide, tar and other toxic constituents present in the smoke of the beedi (12).It may also be found from the results of this study, that the ratio FEV1/FVC\% of beedi smokers was significantly $(\mathrm{P}<0.01)$ less than cigarette smokers.

The type of smoking and pack-years influenced FVC and FEV1, mainly pack-years contributed greater percentage on reduction of FVC and FEV1. It may be inferred from the results that the type of smoking accounted for significant reduction in flow rate. On the whole, beedi smokers showed the lowest value of pulmonary function parameters compared to cigarette smokers and subjects who smoked both beedi and cigarette. 
The results of the present study are similar to the studies by Mosharraf-Hossain KM et al.(13) Shrril DL et al.(14) and ChhabraSK et al.(15) i.e., smoking has a negative impact on most measures of lung functions.

The studies done by Underdorben M et al.(16) Sherril DL et al.(11) Siatkowska $\mathrm{H}$ et al.(17) Islam SS and Schottenfeld D.(18) show the chronic smoking related changes in pulmonary function are reflected as accelerated decrease in FEV1. The lung functions also showed a decline with increasing number of pack years, as seen in our study. Smokers with decreased value of FEV1 were more likely to develop systemic hypertension, coronary diseases and COPD.

Considering the economic status, beedi smokers were predominately seen in the lower income group, while in the higher income group, cigarette smoking is more common. Beedi smoking is the main form of smoking among illiterates and the less educated people while cigarette smoking is more common among the educated population.

\section{CONCLUSION}

Smoking is a major public health problem and a major cause of many preventable diseases and premature deaths all over the world.

Pulmonary function variables will differ based on type of smoking i.e. Beedi smokers, cigarette smokers, who smoked both beedi and cigarette. In summary seems to that all pulmonary function values shows significant reduction in beedi smokers than people who smoke both beedi and cigarette followed by cigarette smokers.

The present study has implications for tobacco control policies. While cigarette packs carry a statutary warning about their harmful effects, beedi packs do not have any such warning. Moreover, as the habit of beedi smoking is more common among the economically underprivileged and those with a poor educational status, health education programmes aimed at reducing the smoking habit would be more difficult to implement and would need to be developed especially to cater to these segment of the population.

\section{REFERENCES}

1. Abdullah ASM, Husten CG. Promotion of smoking cessation in developing countries: a framework for urgent public health interventions. Thorax 2004; 59: 623-630.

2. Chhabra SK. Role of air pollution in respiratory morbidity in Delhi. Proceedings of Workshop on integrated approach to vehicular pollution control in Delhi, World Bank-Government of NCT of Delhi, 16-18 April, 1998,171-80.

3. Malik SK. Chronic bronchitis in beedi smokers. Indian J Chest Dis 1974; 16 : 94-99.
4. Bhinde S V, Jayant Kand Pakhale S S. Chemical analysis of smoke of Indian Cigarettes, bidis and other indigenous forms of smoking levels of steam-volatile phenol, hydrogen cyanide and benzopyrene. Indian Journal of Chest Diseases and Allied Sciences 1990; 32(2):75-81.

5. WalterS and Boyapati J. Longitudnal study of lung function development in a cohort of Indian medical students: Interaction of respiratory allergy and smoking. Indian Journal Physiol Pharmacol 1991; 35(1):44-48.

6. Jayant K, Balakrishnan V, Sanghvi LD, Jussawalia DJ. Quantifications of the role of

7. Smoking and chewing habits in oral, pharyngeal and esophageal cancers. Br J Cancer 1977; 35: 232-235.

8. Notani PN, Sanghvi LD. A retrospective study of lung cancer in Bombay. Br J Cancer 1974; 29: 477-482.

9. Jussawalla DJ, Jain DK. Lung cancer in Greater Bombay: Correltations with religion and smoking habit. $\mathrm{Br} \mathrm{J}$ Cancer 1979; $40:$ 437-38.

10. Sanghvi LD, Rao KCM, Khanolkar VR. Smoking and chewing of tobacco in relation to cancer of the upper alimentary tract. Br Med J 1955; 1 : 1111-14.

11. Jayant K, Balakrishnan V, Sanghvi LD, Jussawalla DJ. Quantifications of the role of smoking and chewing habits in oral, pharyngeal and oesophageal cancers. Br J Cancer 1977; 35 : 232-35.

12. Malik SK. Chronic bronchitis and ventilator impairment in beedi smokers. A follow

13. Mosharraf-Hossain KM, Islam S, Kalam Azzad A, Pasha MM, Sultana F, Hossain RZ, Amin A, Murshed KM. Detection of Chronic Obstructive Pulmonary disease using spirometric screening. Mymensingh Med J. 2009 Jan; 18 (suppl): S 108-112.

14. Sherril DL, Lebowitz MD, Knudson RJ, Burrows B. Longitudnal methods for describing the relationship. Eur Respir J 1993 Marc; 6(3):342-8.

15. Chhabra SK, Rajpal S, Gupta R. Pattern of smoking in Delhi and comparison of chronic respiratory morbidity among beedi and cigarette smokers. Indian J Chest Diseases and Allied Sciences 2001; 43(1): 19-26.

16. Unverdorben M, Mostert A, Munjal S, Vander Bill A, Potgreter L, Venter C, Liang Q, Meyer B, Roething HJ. Acute effects of cigarette smoking on pulmonary functions.

Reqil Toxicol Pharmacol 2010 Jul-Aug; 57(2-3):241-6.

17. Siatkowska H, Jastrzebski D, Kozielski J. Smoking and clinical manifestations, lung function impairement resulting comorbidities. Pol Merkur Lekarski. 2010 July; 29(169):8-13.

18. Islam SS, Schottenfeld D. Declining FEV1 and chronic productive cough in cigarette smokers: a 25 year prospective study of lung cancer incidence in Tecumseh, Michigan. Cancer Epidermal Biomarkers Prev 1994 Jan; 3(4):289-298. 